\title{
Dietary nitrate enhances arterial oxygen saturation after dynamic apnea
}

\author{
A. Patrician ${ }^{1}$, E. Schagatay ${ }^{1,2}$ \\ ${ }^{1}$ Department of Health Sciences, Mid Sweden University, Östersund, Sweden, ${ }^{2}$ Swedish Winter Sports Research Centre, Mid \\ Sweden University, Östersund, Sweden \\ Corresponding author: Alexander Patrician, Environmental Physiology Group, Department of Health Sciences, Mid Sweden \\ University, Kunskapens väg 8, SE 83125 Östersund, Sweden. Tel.: + 46 702229842, Fax: + 46 63165740, E-mail: \\ alexander.patrician@miun.se
}

Accepted for publication 1 March 2016

\begin{abstract}
Breath-hold divers train to minimize their oxygen consumption to improve their apneic performance. Dietary nitrate has been shown to reduce the oxygen cost in a variety of situations, and our aim was to study its effect on arterial oxygen saturation $\left(\mathrm{SaO}_{2}\right)$ after dynamic apnea (DYN) performance. Fourteen healthy male apnea divers (aged $33 \pm 11$ years) received either $70 \mathrm{~mL}$ of concentrated nitrate-rich beetroot juice (BR) or placebo (PL) on different days. At $\mathbf{2 . 5} \mathrm{h}$ after ingesting the juice, they were asked to perform $2 \times 75 \mathrm{~m}$ DYN dives in a pool with 4.5-min recovery between dives. Each dive started
\end{abstract}

after 2-min countdown and without any warm-up apneas, hyperventilation, or lung packing. $\mathrm{SaO}_{2}$ and heart rate were measured via pulse oximetry for $90 \mathrm{~s}$ before and after each dive. Mean $\mathrm{SaO}_{2}$ nadir values after the dives were $83.4 \pm 10.8 \%$ with $\mathrm{BR}$ and $78.3 \pm 11.0 \%$ with $\mathrm{PL}$ $(P<0.05)$. At 20 -s post-dive, mean $\mathrm{SaO}_{2}$ was $86.3 \pm 10.6 \%$ with $\mathrm{BR}$ and $79.4 \pm 10.2 \%$ with $\mathrm{PL}$ $(P<0.05)$. In conclusion, BR juice was found to elevate $\mathrm{SaO}_{2}$ after 75-m DYN. These results suggest an oxygen conserving effect of dietary nitrate supplementation, which likely has a positive effect on maximal apnea performance.
Interest in dietary nitrate $\left(\mathrm{NO}_{3}^{-}\right)$has increased over the past decade because acute ingestion has been shown to improve sports performance in a number of different conditions by reducing the oxygen $\left(\mathrm{O}_{2}\right)$ cost and enhancing tolerance to exercise of healthy subjects in normoxia (Larsen et al., 2007; Bailey et al., 2009; Lansley et al., 2011; Breese et al., 2013; Kelly et al., 2014), in hypoxia (Vanhatalo et al., 2011; Masschelein et al., 2012; Kelly et al., 2014) and in patients with peripheral artery disease (Kenjale et al., 2011).

The mechanism responsible for the $\mathrm{O}_{2}$ conserving effect of $\mathrm{NO}_{3}^{-}$is not clear. An improvement in mitochondrial efficiency is a potential explanation for a lower $\mathrm{O}_{2}$ cost of submaximal exercise (Larsen et al., 2011). A lower adenosine triphosphate (ATP) requirement for the same power output is another explanation (Bailey et al., 2010) that could lower $\mathrm{O}_{2}$ cost even if mitochondrial efficiency is unchanged (Whitfield et al., 2015).

Sports involving apneic diving rely completely on stored $\mathrm{O}_{2}$, and therefore provide a unique model to study $\mathrm{O}_{2}$ consumption. Competitive breath-hold diving is a growing sport, with disciplines that aim for maximal performance in underwater time (static apnea), horizontal distance (dynamic apnea) with (DYN) or without fins, or depth. Performance depends upon a number of physiological factors, but achieving a minimal rate of $\mathrm{O}_{2}$ consumption $\left(\mathrm{VO}_{2 \mathrm{~min}}\right)$ is essential for success in all disciplines (Ferretti, 2001; Foster \& Sheel, 2005; Schagatay, 2009, 2010, 2011).

During apnea, the results have however been conflicting whether $\mathrm{NO}_{3}^{-}$ingestion enhances performance. Acute $\mathrm{NO}_{3}^{-}$ingestion via beetroot juice was found to increase arterial $\mathrm{O}_{2}$ saturation $\left(\mathrm{SaO}_{2}\right)$ after static apnea of a fixed duration, it caused greater driving bradycardia during maximal apneas, and it also prolonged maximal apnea duration by $11 \%$, compared to placebo (Engan et al., 2012). However, a study by Schiffer et al. (2013) reported that $\mathrm{NO}_{3}^{-}$ supplementation via potassium $\mathrm{NO}_{3}^{-}$reduced static apneic duration and enhanced desaturation during maximal duration static apneas. Yet in the same study, after simulated dynamic apnea by stationary cycling, a trend for increased $\mathrm{SaO}_{2}$ after maximal duration apneas was reported with $\mathrm{NO}_{3}^{-}$supplementation (Schiffer et al., 2013).

Dynamic apnea performance relies on factors also important during static apnea - total body storage of 
usable $\mathrm{O}_{2}$, tolerance to asphyxia, and metabolic rate (Schagatay, 2009), but contains the added challenges of sustaining propulsive work despite the diving response (vasoconstriction and bradycardia) and central pooling of blood to high priority regions (Scholander et al., 1962; Gooden, 1994; Schagatay, 2010).

Our objective was to determine if acute $\mathrm{NO}_{3}^{-}$ ingestion would enhance $\mathrm{SaO}_{2}$ after a fixed distance dive. We therefore studied the effect of dietary $\mathrm{NO}_{3}^{-}$ on $\mathrm{SaO}_{2}$ and heart rate after DYN in a pool. $\mathrm{SaO}_{2}$ after the dive would reflect the $\mathrm{O}_{2}$ consumption, which would likely be predictive also of maximal DYN performance. The heart rate recovery response could reflect the magnitude of vasoconstriction of the diving response occurring during the dive. We hypothesize that $\mathrm{NO}_{3}^{-}$will decrease the $\mathrm{O}_{2}$ cost and increase the diving response.

\section{Methods}

Subjects

Fourteen healthy male subjects (mean \pm SD age $33 \pm 11$ years, height $182 \pm 8 \mathrm{~cm}$ and weight $82 \pm 12 \mathrm{~kg}$ ) volunteered to participate in this study. They were all experienced apneic divers with $5.0 \pm 3.8$ years of training in the sport with a DYN personal best of $119 \pm 43 \mathrm{~m}$. Most divers were close to their peak training level; eight were tested in connection with a major competition, two were safety divers for the competition who trained regularly, and four were tested after a training camp. Subjects gave their written informed consent after receiving written and oral information about the study procedures and potential risks. The protocol had been approved by the local research ethics committee and was conducted in accordance with the Helsinki declaration.

\section{Methodological considerations}

No maximal effort DYN dives were included, as they may lead to syncope, which is an unnecessary risk that would require a full-scale safety system with two safety divers in the water. In addition, the maximal performance varies from dayto-day due to both physiological and psychological factors, especially in trained athletes (Schagatay, 2010). The authors considered that the submaximal performance of $75 \mathrm{~m}$ would be more standardized and would produce an $\mathrm{O}_{2}$ debt sufficient enough to conclude whether dietary $\mathrm{NO}_{3}^{-}$had an effect on performance or not. The 75-m dives were performed as part of their training. Only trained apneists were included because of their ability (compared to non-divers) to manage the $\mathrm{O}_{2}$ debt when performing $75-\mathrm{m}$ DYN. A safety diver was present at the poolside during all events.

\section{Experimental procedures}

Subjects were assigned in a blinded, randomized, cross-over design to receive dietary supplementation with $70 \mathrm{~mL}$ of concentrated $\mathrm{NO}_{3}^{-}$-rich beetroot (BR) or placebo (PL) juice on different days. The BR juice contained $\sim 5.0 \mathrm{mmol} \mathrm{NO}_{3}^{-}$and the PL contained $\sim 0.003 \mathrm{mmol} \mathrm{NO}-$ (James White Drinks Ltd., Ipswich, UK). BR is indistinguishable from PL in color, taste, smell, and texture (Lansley et al., 2011). Subjects were instructed to consume the beverage $2.5 \mathrm{~h}$ prior to each test, which were conducted on different days with at least $24 \mathrm{~h}$ between tests.

Each subject sat resting on a chair at the poolside for $5 \mathrm{~min}$ prior to entering the water (Fig. 1). In the water after an additional 2-min rest, baseline $\mathrm{SaO}_{2}$ and heart rate were measured via finger pulse oximetry (Nonin Medical Inc., Plymouth, Minnesota, USA) every $10 \mathrm{~s}$ for a total of $90 \mathrm{~s}$. Each dive was preceded by a 2 -min countdown without any warm-up, hyperventilation, or lung packing, as these maneuvers may affect diving performance and are difficult to standardize. Warm-up apneas can pre-stimulate the spleen to release red blood cells that may prolong apneas (Schagatay et al., 2001), hyperventilation reduces the level of carbon dioxide $\left(\mathrm{CO}_{2}\right)$ and urge to breathe (Lin et al., 1974) and may cause hypocapnia-induced cerebral vasoconstriction (Brian, 1998), and lung packing increases the $\mathrm{O}_{2}$ stores (Örnhagen et al., 1998). Subjects were then asked to perform $2 \times 75 \mathrm{~m} \mathrm{DYN}$ in the pool with 4.5 min recovery between the dives. Starting within $10 \mathrm{~s}$ after surfacing after each $75 \mathrm{~m} \mathrm{DYN}, \mathrm{SaO}_{2}$ and heart rate were measured continuously until $90 \mathrm{~s}$ after each dive. The $\mathrm{SaO}_{2}$ nadir was defined as the lowest $\mathrm{SaO}_{2}$ value recorded from each dive in the 90 -s post-dive period. Water temperature was $26 \pm 1{ }^{\circ} \mathrm{C}$ and air temperature was $32 \pm 2{ }^{\circ} \mathrm{C}$, inducing a thermal difference sufficient to enhance the diving response compared to apnea alone (Schagatay \& Holm, 1996).

\section{Data analysis}

All subjects served as their own controls and all but one subject completed all tests; the one subject interrupted the second swim before $75 \mathrm{~m}$. Another three subjects had incomplete data from one of their $75-\mathrm{m}$ swims. For these four subjects, calculations were based on one dive from each condition, in the same dive order (dive 1 or 2) to avoid an order effect. Therefore, 10-s group mean values were calculated using the means of two dives in nine subjects and one dive in four subjects in each of the BR and $\mathrm{PL}$ conditions. One subject was excluded from the 10-s group mean value analysis, but not the $\mathrm{SaO}_{2}$ nadir value comparison, because a complete data from each dive were not in the same dive order. Data are presented as mean $\pm \mathrm{SD}$, in 14 subjects for the $\mathrm{SaO}_{2}$ nadir values, and in 13 subjects for the continuous $\mathrm{SaO}_{2}$ and heart rate values. The lowest individual post-dive $\mathrm{SaO}_{2}$ nadir value was used for calculating mean $\mathrm{SaO}_{2}$ nadir values. $\mathrm{SaO}_{2}$ rates of recovery after surfacing were calculated from $\mathrm{SaO}_{2}$ nadir to $97 \% \mathrm{SaO}_{2}$.

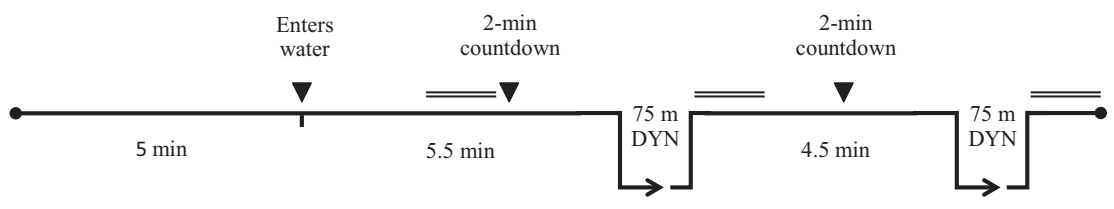

Fig. 1. The experimental procedure consisting of $2 \times 75 \mathrm{~m}$ dynamic apnea with fins (DYN) with 4.5 -min recovery between the dives. = Line signifies the 90 -s measurement of $\mathrm{SaO}_{2}$ and heart rate. 


\section{Statistics}

Wilcoxon matched-pairs signed rank test was used to compare $\mathrm{SaO}_{2}$ and heart rate between BR and PL conditions. Bonferroni correction was used for multiple comparisons of up to $40 \mathrm{~s}$ after surfacing. Statistical significance was accepted at $P \leq 0.05$.

\section{Results}

Arterial $\mathrm{O}_{2}$ saturation

The resting control $\mathrm{SaO}_{2}$ was $98.2 \pm 0.7 \%$ with $\mathrm{BR}$ and it was $98.1 \pm 0.5 \%$ with PL $(P=0.481)$. Mean of individual $\mathrm{SaO}_{2}$ nadir values were $83.4 \pm 10.8 \%$ with $\mathrm{BR}$ and $78.3 \pm 11.0 \%$ with PL $(P=0.023)$. The reductions from resting control values to $\mathrm{SaO}_{2}$ nadir were $14.8 \pm 11.0 \%$ with $\mathrm{BR}$ and $19.8 \pm 11.1 \%$ with PL $(P=0.027$; Fig. 2$)$. At 20 -s post-dive, mean $\mathrm{SaO}_{2}$ was $86.3 \pm 10.6 \%$ with $\mathrm{BR}$ and $79.4 \pm 10.2 \%$ with PL $(P=0.019$; Figs 3 and 4). There were no differences between BR and PL in the ensuing 10-s intervals across recovery. Mean rate of $\mathrm{SaO}_{2}$ recovery from $\mathrm{SaO}_{2}$ nadir to $97 \%$ was

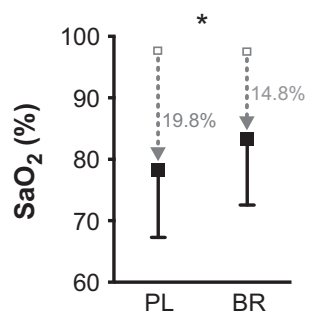

Fig. 2. Mean $\pm \mathrm{SD}(n=14)$ for $\mathrm{SaO}_{2}$ nadir with beetroot (BR) and placebo (PL) juice after 75-m dynamic apnea (DYN). The "open" and "closed" squares, respectively, represent the mean $\mathrm{SaO}_{2}$ for baseline and after the DYN. Values inserted are the percent reduction from baseline $\mathrm{SaO}_{2}$ before the DYN to $\mathrm{SaO}_{2}$ nadir values $(* P<0.05)$.

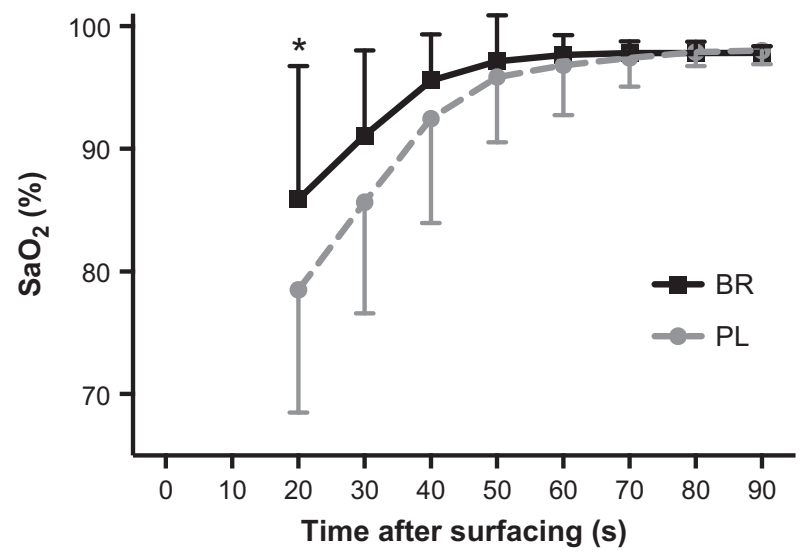

Fig. 3. Mean $\pm \mathrm{SD}(n=13)$ arterial oxygen saturation $\left(\mathrm{SaO}_{2}\right)$ with beetroot $(\mathrm{BR})$ and placebo $(\mathrm{PL})$ juice during $90 \mathrm{~s}$ of recovery after $75 \mathrm{~m}$ dynamic apnea (DYN). Zero (" 0 ") indicates the moment the diver surfaces $(* P<0.05)$.
$0.8 \pm 0.6 \% / \mathrm{s}$ with $\mathrm{BR}$ and $0.9 \pm 0.5 \% / \mathrm{s}$ with $\mathrm{PL}$ $(P=0.340)$.

\section{Heart rate}

The resting control heart rate was $72 \pm 12$ beats/min with BR and $76 \pm 15$ beats/min with PL $(P=0.727)$. There were no significant differences in heart rate between $\mathrm{BR}$ and $\mathrm{PL}$ conditions after the dives (Fig. 5).

\section{Discussion}

The principal finding was that $\mathrm{SaO}_{2}$ after 75-m DYN was higher after BR ingestion compared to PL. This was true both for the mean nadir $\mathrm{SaO}_{2}$ and the $\mathrm{SaO}_{2}$ at the point $20 \mathrm{~s}$ after the dive, suggesting that BR reduces the $\mathrm{O}_{2}$ cost of exercise during dynamic apnea.

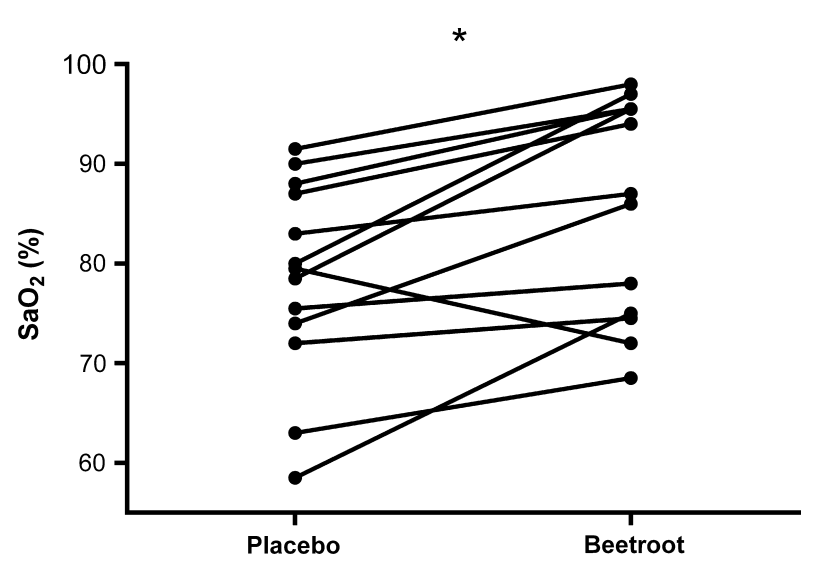

Fig. 4. Individual mean arterial oxygen saturation $\left(\mathrm{SaO}_{2}\right.$; $n=13$ ) between placebo and beetroot juice $20 \mathrm{~s}$ after surfacing from $75-\mathrm{m}$ dynamic apnea (DYN; $\left.{ }^{*} P<0.05\right)$.

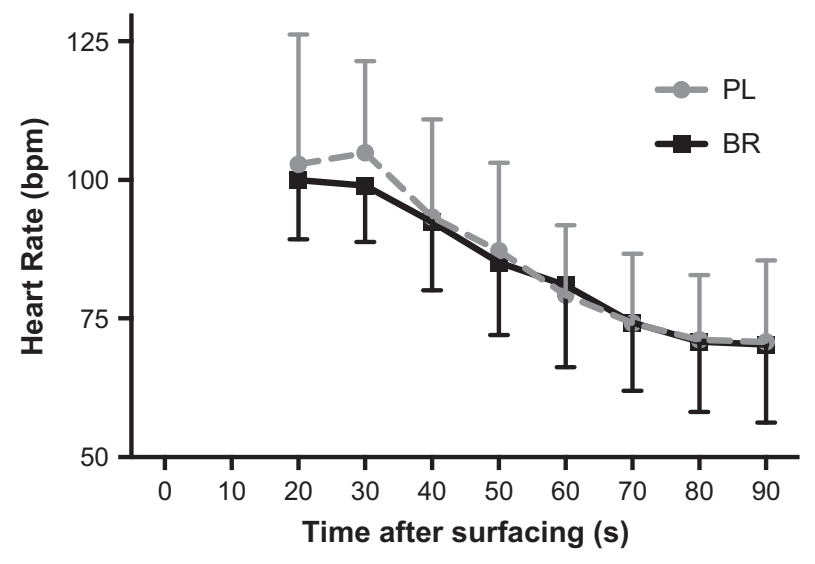

Fig. 5. Mean $\pm \mathrm{SD}(n=13)$ heart rate with beetroot (BR) and placebo (PL) juice during $90 \mathrm{~s}$ of recovery after $75-\mathrm{m}$ dynamic apnea (DYN). Zero ("0") indicates the moment the diver surfaces. 
This finding aligns with results from an apneic model without exercise (Engan et al., 2012) and with the tendency for $\mathrm{O}_{2}$ conservation observed in another exercise-apnea model (Schiffer et al., 2013). It also aligns with several studies involving eupneic exercise in normoxia (Larsen et al., 2007; Bailey et al., 2009; Lansley et al., 2011; Breese et al., 2013; Kelly et al., 2014) and in hypoxia (Vanhatalo et al., 2011; Masschelein et al., 2012; Kelly et al., 2014). The result suggests that the total apneic duration and the total distance covered in DYN would likely be increased during a maximal attempt, due to increased remaining $\mathrm{O}_{2}$ stores (Schagatay, 2010).

Engan et al. (2012), who concluded there was an $\mathrm{O}_{2}$ conserving effect during static apnea, used similar $\mathrm{NO}_{3}^{-}$administration procedures as in this study, and did not incorporate warm-up apneas or allow subjects to hyperventilate (Schagatay et al., 2001; Rasmussen et al., 2006). In Schiffer et al. (2013), who reported the contrary effect, a different $\mathrm{NO}_{3}^{-}$administration was used, and warm-up apneas and hyperventilation were not controlled for, which could have contributed to their different results. Varying warmup procedures likely play important roles in the outcome of physiological responses during static apnea performance (Schagatay, 2009) after consuming dietary $\mathrm{NO}_{3}^{-}$. Interesting, however, is the effect during exercise of $\mathrm{NO}_{3}^{-}$supplementation in the study by Schiffer et al. (2013), where their data show a tendency for the same $\mathrm{O}_{2}$-conserving effect as seen in the current study.

There was no effect of BR on heart rate in neither the current study nor in Schiffer et al. (2013), while Engan et al. (2012) found that the diving bradycardia was more pronounced in maximal static apneas. $\mathrm{NO}_{3}^{-}$supplementation has been shown to reduce the $\mathrm{O}_{2}$ cost during submaximal exercise (Larsen et al., 2007; Bailey et al., 2009), and during the submaximal effort in the current study, but it did not appear from the heart rate response that an accumulated $\mathrm{O}_{2}$ debt occurred with BR. An aspect unique to the current study is the inclusion of immersion, particularly facial immersion (de Bruijn et al., 2009) which has been shown to be an important contributor to apneic performance by augmenting the diving response (Schuitema \& Holm, 1988). A fully activated diving response due to a thermal stimulus, could provide beneficial conditions during exercise, when an $\mathrm{O}_{2}$ conserving effect is even more essential than compared to rest. Therefore, it would be interesting to further investigate the influence of $\mathrm{BR}$ on the cardiovascular diving response during submaximal exercise.

From the moment the diver surfaces, time is required to dry the hand and allow the pulse oximeters to obtain a reliable reading, resulting in a first usable value about $10-15$ s after surfacing. Consequently, the focus of the analysis was set on the period from $15 \mathrm{~s}$ and onwards. Measuring $\mathrm{SaO}_{2}$ from the hand is favorable in this case, compared to the ear for example, due to the longer circulation time between the lungs, heart, and the finger. A delay of approximately 15-20 s occurs before the $\mathrm{SaO}_{2}$ nadir corresponding to the end of apnea appears in the finger (Andersson \& Evaggelidis, 2009), thus we could likely detect the nadir values.

In conclusion, BR juice was found to result in a higher $\mathrm{SaO}_{2}$ after $75-\mathrm{m}$ DYN. These results suggest an $\mathrm{O}_{2}$-conserving effect of dietary $\mathrm{NO}_{3}^{-}$supplementation, which increases the safety margins of submaximal dives and potentially has a positive effect on maximal apnea performance.

$\mathrm{NO}_{3}^{-}$supplementation could also be applied to other sporting activities with limited oxygen availability, e.g., swimming where breathing is restricted to optimize hydrodynamics, competition apnea, spearfishing, synchronized swimming, and underwater team sports such as underwater rugby and hockey. Short-term supplementation with beetroot juice has also been shown to improve the walking time performance of patients with peripheral arterial disease (Kenjale et al., 2011), counteract the decline in endothelial function occurring during ascent to high altitude environments (Bakker et al., 2015) and preserve muscle oxygenation during exercise in acute normobaric hypoxia (Masschelein et al., 2012).

\section{Perspectives}

The $\mathrm{O}_{2}$-conserving effect of dietary $\mathrm{NO}_{3}^{-}$could likely be beneficial in various sports involving apnea, e.g., apnea diving, spearfishing, swimming, synchronized swimming and underwater rugby, and hockey. Effects in apneic-related sports would be expected on several levels; by increasing safety margins in submaximal dives, potentially increasing maximal performance in competition, and by reducing recovery time between short, repeated dives. Other applications of dietary $\mathrm{NO}_{3}^{-}$supplementation could possibly be found in exercise at high altitude where the $\mathrm{O}_{2}$ supply is also limited.

Key words: Apneic diving, breath-hold, hypoxia, immersion, arterial desaturation, anaerobic exercise, nitrate, sport performance.

\section{Acknowledgements}

We thank the apnea divers for their participation, as well as the coaches and organizers of the events for their help in conducting the study. The study was supported by the Swedish National Centre for Research in Sports. 


\section{References}

Andersson JPA, Evaggelidis L. Arterial oxygen saturation and diving response during dynamic apneas in breath-hold divers. Scand J Med Sci Sports 2009: 19: 87-91.

Bailey SJ, Fulford J, Vanhatalo A, Winyard PG, Blackwell JR, DiMenna FJ, Wilkerson DP, Benjamin N, Jones AM. Dietary nitrate supplementation enhances muscle contractile efficiency during knee-extensor exercise in humans. J Appl Physiol 2010: 109: 135-148.

Bailey SJ, Winyard P, Vanhatalo A, Blackwell JR, Dimenna FJ, Wilkerson DP, Tarr J, Benjamin N, Jones AM. Dietary nitrate supplementation reduces the $\mathrm{O}_{2}$ cost of low-intensity exercise and enhances tolerance to high-intensity exercise in humans. J Appl Physiol 2009: 107: 1144-1155.

Bakker E, Engan H, Patrician A, Schagatay E, Karlsen T, Wisløff U, Gaustad SE. Acute dietary nitrate supplementation improves arterial endothelial function at high altitude: a double-blinded randomized controlled cross over study. Nitric Oxide 2015: 50: 58-64.

Brian JE. Carbon dioxide and the cerebral circulation. Anesthesiology 1998: 88: 1365-1386.

Breese BC, McNarry MA, Marwood S, Blackwell JR, Bailey SJ, Jones AM. Beetroot juice supplementation speeds $\mathrm{O}_{2}$ uptake kinetics and improves exercise tolerance during severe-intensity exercise initiated from an elevated metabolic rate. Am J Physiol Regul Integr Comp Physiol 2013: 305: R1441-R1450.

de Bruijn R, Richardson M, Schagatay E. Oxygen-conserving effect of the diving response in the immersed human. Diving Hyperb Med 2009: 39: 193-199.

Engan HK, Jones AM, Ehrenberg F, Schagatay E. Acute dietary nitrate supplementation improves dry static apnea performance. Respir Physiol Neurobiol 2012: 182: 53-59.

Ferretti G. Extreme human breath-hold diving. Eur J of Appl Physiol 2001: 84: 254-271.
Foster GE, Sheel AW. The human diving response, its function, and its control. Scand J Med Sci Sports 2005: 15: 3-12.

Gooden BA. Mechanism of the human diving response. Integr Physiol Behav Sci 1994: 29: 6-16.

Kelly J, Vanhatalo A, Bailey SJ, Wylie LJ, Tucker C, List S, Winyard PG, Jones AM. Dietary nitrate supplementation: effects on plasma nitrite and pulmonary $\mathrm{O}_{2}$ uptake dynamics during exercise in hypoxia and normoxia. Am J Physiol Regul Integr Comp Physiol 2014: 307: R920-R930.

Kenjale AA, Ham KL, Stabler T, Robbins JL, Johnson JL, VanBruggen M, Privette G, Yim E, Kraus WE, Allen JD. Dietary nitrate supplementation enhances exercise performance in peripheral arterial disease. J Appl Physiol 2011: 110: 1582-1591.

Lansley KE, Winyard PG, Fulford J, Vanhatalo A, Bailey SJ, Blackwell JR, DiMenna FJ, Gilchrist M, Benjamin N, Jones AM. Dietary nitrate supplementation reduces the $\mathrm{O}_{2}$ cost of walking and running: a placebo-controlled study. J Appl Physiol 2011: 110: 591-600.

Larsen FJ, Schiffer TA, Borniquel S, Sahlin K, Ekblom B, Lundberg JO, Weitzberg E. Dietary inorganic nitrate improves mitochondrial efficiency in humans. Cell Metab 2011: 13: 149-159.

Larsen FJ, Weitzberg E, Lundberg JO, Ekblom B. Effects of dietary nitrate on oxygen cost during exercise. Acta Physiol 2007: 191: 59-66.

Lin YC, Lally DA, Moore TO, Hong SK. Physiological and conventional breath-hold breaking points. J Appl Physiol 1974: 37: 291-296.

Masschelein E, Van Thienen R, Wang X, Van Schepdael A, Thomis M, Hespel P. Dietary nitrate improves muscle but not cerebral oxygenation status during exercise in hypoxia. $\mathbf{J}$ Appl Physiol 2012: 113: 736-745.

Örnhagen H, Schagatay E, Andersson J, Bergsten E, Gustafsson P, Sandström S. Mechanisms of "buccal pumping" ("lung packing") and its pulmonary effects. 24th Annual Scientific Meeting of the European Underwater and Baromedical Society, 1998: 80-83.

Schagatay E. Predicting performance in competitive apnoea diving. Part I: static apnoea. Diving Hyperb Med 2009: 39: 88-99.

Schagatay E. Predicting performance in competitive apnea diving. Part II: dynamic apnea. Diving Hyperb Med 2010: 40: 11-22.

Schagatay E. Predicting performance in competitive apnea diving. Part III: deep diving. Diving Hyperb Med 2011: 41: 216-228.

Schagatay E, Andersson JPA, Hallén M, Pålsson B. Selected contribution: role of spleen emptying in prolonging apneas in humans. J Appl Physiol 2001: 90: 1623-1629.

Schagatay E, Holm B. Effects of water and ambient air temperatures on human diving bradycardia. Eur $\mathbf{J}$ Appl Physiol 1996: 73: 1-6.

Schiffer TA, Larsen FJ, Lundberg JO, Weitzberg E, Lindholm P. Effects of dietary inorganic nitrate on static and dynamic breath-holding in humans. Respir Physiol Neurobiol 2013: 185: 339-348.

Scholander PF, Hammel HT, LeMessurier H, Hemmingsen E, Garey W. Circulatory adjustment in pearl divers. J Appl Physiol 1962: 17: 184-190.

Schuitema K, Holm B. The role of different facial areas in eliciting human diving bradycardia. Acta Physiol Scand 1988: 132: 119-120.

Vanhatalo A, Fulford J, Bailey SJ, Blackwell JR, Winyard PG, Jones AM. Dietary nitrate reduces muscle metabolic perturbation and improves exercise tolerance in hypoxia. J Physiol 2011: 589: $5517-$ 5528.

Whitfield J, Ludzki A, Heigenhauser G, Spriet L, Holloway G. Beetroot juice supplementation does not improve mitochondrial efficiency or ADP sensitivity in humans. FASEB J 2015: 29: 824. 